\title{
Comparison of Duration of En-Masse Anterior Retraction using Friction and Frictionless Mechanics
}

\author{
Research Article
}

Arathi Murugesan ${ }^{1}$, Saravana Dinesh $\mathrm{SP}^{2^{*}}$, Nivethigaa Balakrishnan ${ }^{3}$

${ }^{1}$ Department of Orthodontics and Dentofacial Orthopedics, Saveetha Dental College and Hospitals, Saveetha Institute of Medical and Technical Sciences, Saveetha University, Chennai, India.

${ }^{2}$ Professor and Head of the Department, Department of Orthodontics and Dentofacial Orthopedics, Saveetha Dental College and Hospitals, Saveetha Institute of Medical and Technical Sciences, Saveetha University, Chennai, India.

${ }^{3}$ Senior Lecturer, Department of Orthodontics and Dentofacial Orthopedics, Saveetha Dental College and Hospitals, Saveetha Institute of Medical and Technical Sciences, Saveetha University, Chennai, India.

\section{Abstract}

Objectives: The aim of the study was to compare the duration of en masse anterior retraction using friction and frictionless mechanics.

Methods: This was a retrospective study that involved the records of 104 orthodontic patients who underwent en masse anterior retraction. They were equally divided into two groups based on the method of retraction mechanics used, namely, friction and frictionless mechanics. The duration of retraction in each group was assessed and compared using Independent sample t-test.

Results: $\mathrm{p}$ - value of 0.077 for a confidence interval of $95 \%$ was obtained indicating no statistical significant difference among the two groups.

Conclusion: Friction and frictionless mechanics are clinically efficient for en masse anterior retraction in terms of duration of retraction.

Keywords: Retraction; Friction Mechanics; Frictionless Mechanics; Space Cosure; En-Masse Anterior Retraction; Retraction.

\section{Introduction}

In most clinical situations orthodontic treatment objectives may indicate extraction of the first premolar either for the relief of crowding, reduction of dentoalveolar protrusion and improving the facial esthetics, or correction of inter-arch mal-relationships through dental camouflage. Hence retraction is one of the main procedures carried out during orthodontic treatment. In many patients the retraction procedure takes a long duration of the entire orthodontic treatment.

Two retraction mechanics are known, namely, friction (sliding mechanics) or frictionless mechanics. The friction created between archwire and bracket when pulling the anterior distally using sliding mechanics is influenced by many factors. Among the factors, surface conditions of the archwires and bracket slot, wire section, torque at the wire-bracket interface, type and force of ligation, use of self-ligating brackets, inter-bracket distance, saliva, and influence of oral function are the most common [1, 2]. Various techniques are being used including Nickel-titanium coil springs and elastomeric chains. On the other hand frictionless mechanics includes use of Burstone's T loop, Ricket's spring, Gjesing's spring [3] and many other loops or springs.

A major challenge during retraction is anchorage control. For minimizing anchorage loss and maximizing tooth movement efficiently, Tweed [4-6] emphasized anchorage preparation as the first step in orthodontic treatment. Storey and Smith [7] advocated the use of light force values, and Begg [8] emphasized the advantage of differential force to produce the maximum rate of movement of teeth.

To achieve maximum anchorage, separate canine retraction was recommended by Proffit and Fields [9], Roth [10] and Kuhlberg [11]. This was supported by stating that this approach would al-

\footnotetext{
*Corresponding Author:

Saravana Dinesh S.P,

Professor and Head of the Department, Department of Orthodontics and Dentofacial Orthopedics, Saveetha Dental College and Hospitals, Saveetha Institute of Medical and Technical Sciences, Saveetha University, Chennai, India. Postcode- 600077.

E-mail: saravanadinesh@saveetha.com

Received: October 30, 2019

Accepted: November 28, 2019

Published: November 30, 2019

Citation: Arathi Murugesan, Saravana Dinesh SP, Nivethigaa Balakrishnan. Comparison of Duration of En-Masse Anterior Retraction using Friction and Frictionless Mechanics. Int J Dentistry Oral Sci. 2019;S2:02:003:10-13. doi: http://dx.doi.org/10.19070/2377-8075-SI02-02003

Copyright: Saravana Dinesh S.P ${ }^{\circ}$ 2019. This is an open-access article distributed under the terms of the Creative Commons Attribution License, which permits unrestricted use, distribution and reproduction in any medium, provided the original author and source are credited.
} 
low the retraction force to be constantly dissipated over the large periodontal ligament area in the anchor unit.

On the other hand, Staggers and Germane [12] described anchorage as being taxed twice with a two-step retraction, as opposed to once with en masse retraction, pointing out that the posterior segment is unaware of knowing how many teeth are being retracted and merely responds to the force system involved. Heo et al., [13] stated that there is no difference in anchorage loss among the two techniques.

So far, studies have been done to compare the friction and frictionless mechanics only with individual canine retraction. Therefore, the present study aimed to compare the duration of en masse anterior retraction using friction and frictionless mechanics.

\section{Materials and Methods}

This was a retrospective study conducted in the Department of Orthodontics, Saveetha Dental College and Hospitals, Chennai. Treatment records of orthodontic patients who underwent first premolar extraction and required maximum anchorage were retrospectively analysed from the patient data between June 2018 and march 2019.

Sample size was calculated using $G$ power analysis for a power of $80 \%$ and 104 patient records were collected which met the following inclusion and exclusion criteria.

The inclusion criteria for the study were:

- Age group above 18 years

- Both females and males

- 5-7mm of extraction space remained on both sides after leveling and aligning

- En-masse anterior retraction using friction or frictionless mechanics.

The exclusion criteria were:

- Subjects who had a history of broken appliances or irregular appointments.

- Subjects who underwent accelerated orthodontic treatment mechanics.

- Subjects who underwent individual canine retraction followed by incisor retraction.

104 records were equally divided into friction and frictionless groups based on the retraction mechanics used. The date of start of retraction and end of space closure was noted and duration of retraction was calculated for each subject.
SPSS statistics software version 20.0 for Windows was used to do the statistical analysis. Descriptive statistics and independent sample t-test was done to compare the duration of retraction among friction and frictionless mechanics for the entire sample and also for different age groups (20-24 years, 25-28 years and $>28$ years) and gender. p-value was set as 0.05 .

\section{Results}

The mean age group of samples in group 1 and group 2 are 17 $+/-2.3$ years and $17+/-3.9$ years respectively. Male/female ratio of 25/27 and 24/28 were observed in group 1 and group 2 respectively.

Mean and standard deviation of group 1 and group 2 are 7.71 $+/-0.94$ months and $7.38+/-0.93$ months respectively. This mean duration of retraction was observed for closing spaces of about $6.9+/-1.2 \mathrm{~mm}$ and $6.5+/-0.9 \mathrm{~mm}$ in group 1 and group 2 respectively.

Figure 1 represents the mean and standard errors for both the groups. Independent sample t-test to compare the duration of retraction between two groups resulted in a significant value of 0.077 for a confidence interval of $95 \%$ (Table 1). This indicates that there was no statistically significant difference among the two groups. Independent t-test also revealed that there was no significant difference in duration of retraction among friction and frictionless mechanics in different age groups (Figure 2) and gender (Figure 3).

\section{Discussion}

Numerous studies in various aspects of Orthodontics have been conducted by our team over the past several years [3, 14-23]. Currently it interests to study the duration of retraction in friction and frictionless mechanics. The extraction of the first permanent premolars for correction of various malocclusions has become an integral part of the orthodontic treatment procedure. Techniques of space closure are various. However they can be classified under two main mechanics; the loop mechanics which involves the frictionless tooth movement and the continuous mechanics involving friction tooth movement.

Single-stage retraction, otherwise called en masse anterior retraction mechanics was adopted for the present study rather than two stage retraction mechanics. This was because in two stage retraction mechanics, there was an unesthetic space created in the anterior region. Force in the range of $150 \mathrm{~g}$ to $200 \mathrm{~g}$ was applied for all the patients to close the extraction spaces.

Table 1. The table depicts the mean, standard deviation and significance value of independent sample t-test for the two groups. A mean value of 7.71 +/- 0.936 months and $7.38+/-0.932$ was obtained for the groups friction mechanics and frictionless mechanics respectively. Independent sample $t$ test reported a p-value of 0.077 which was greater than 0.05 indicating that there was no statistically significant difference in duration of retraction among the two groups.

\begin{tabular}{|c|c|c|c|}
\hline Groups & Mean (months) & Standard deviation (months) & p-value \\
\hline Friction mechanics & 7.71 & 0.936 & \multirow{2}{*}{0.077} \\
\hline Frictionless mechanics & 7.38 & 0.932 & \\
\hline
\end{tabular}


Figure 1. The bar graph represents mean and standard error for a confidence interval of $95 \%$ for the duration of en masse retraction for friction and frictionless mechanics. $\mathrm{X}$-axis represents the type of mechanics used, namely, friction (blue) and frictionless (green) mechanics and $y$-axis represents the duration of retraction in months tested by Independent sample $t$ test; $p$ value -0.077 ( $p$ value $>0.05$ ). Even though the retraction duration for frictionless mechanics was marginally less than that compared to that of the friction mechanics, it was not statistically significant.

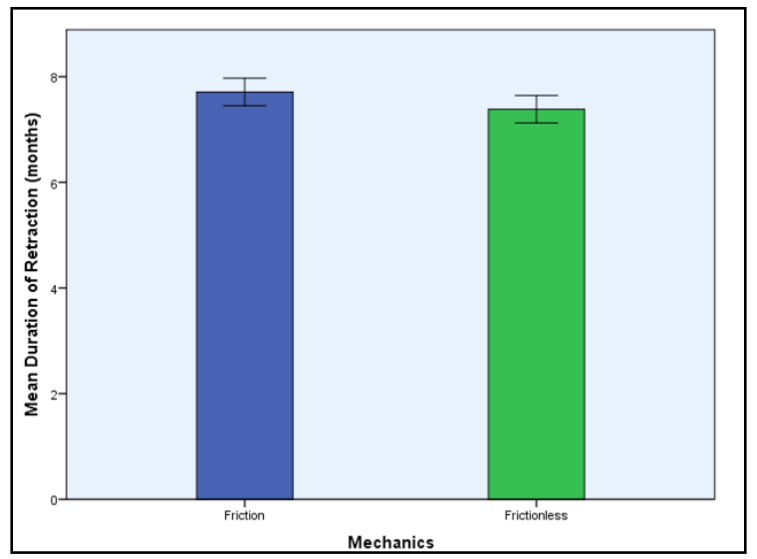

Figure 2. The bar graph depicts the comparison of duration of retraction among friction and frictionless mechanics in different age groups. X-axis represents the three age groups, namely 20-24 years, 35-28 years and above 28 years. Y-axis represents the mean duration of retraction in months. The graph is clustered based on the type of retraction mechanics used, that is, friction (blue) and frictionless (green) mechanics. There was no significant difference in duration of retraction among the two mechanics in different age groups [Independent Sample t test; $p$ value- 0.161 (20-24 years); 0.633 (25-28 years); 0.303 (> 28 years)] even though a marginal increase in duration was seen in friction mechanics in all the three groups.

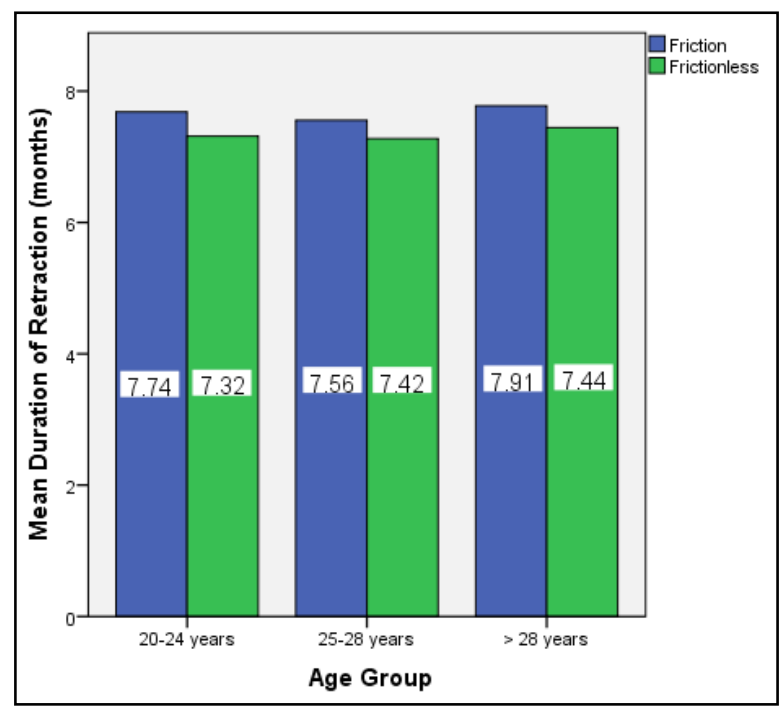

Figure 3. The bar graph depicts the comparison of duration of retraction among friction and frictionless mechanics in males and females. X-axis represents the gender and y-axis represents the mean duration of retraction in months. The graph is clustered based on the type of retraction mechanics used, that is, friction (blue) and frictionless (green) mechanics. There was no significant difference in duration of retraction among the two mechanics in males and females [Independent Sample t test; $\mathrm{p}$ value- 0.335 (males); 0.079 (females)] even though a marginal increase in duration was seen in friction mechanics in both the gender.

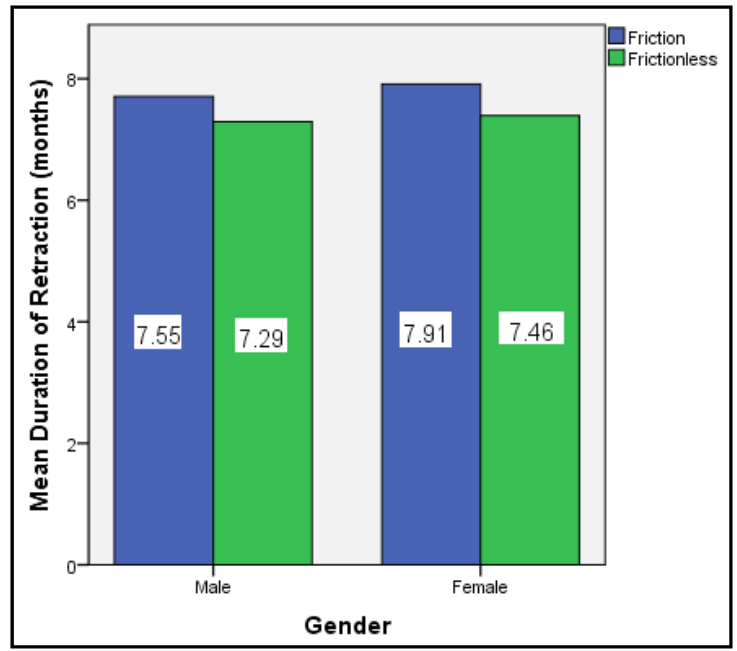


Makhlouf et al., [24] reported space closure of $3.1 \mathrm{~mm}$ in a period of 4 months using NiTi coil spring and $0.3 \mathrm{~mm}$ in 4 months in T loop group for canine retraction. Rhee et al., [25] in an in-vitro study stated friction mechanics had significant rotation control compared to frictionless during canine retraction. Hayashi et al., [26] also reported a similar observation. With the advent of temporary anchorage devices, the possibility of various types of tooth movement of greater magnitude is possible [27-30]. This can be used in both friction and frictionless mechanics to augment anchorage.

In the present study we observed a similar rate of tooth movement and duration of retraction in both friction and frictionless groups. There was no significant amount of anchorage loss in the selected cases. The limitation of the present study is that all the types of loops were included in the frictionless group. The retrospective nature of the study was also a limiting factor which could have resulted in some confounding factors. Future randomized clinical trials comparing rate of retraction, root resorption and type of tooth movement among friction and frictionless mechanics is recommended.

\section{Conclusion}

There was no significant difference in duration of space closure among friction and frictionless mechanics. Thus, both mechanics are clinically efficient in en masse anterior retraction in terms of duration of retraction.

\section{References}

[1]. Leonardi R, Annunziata A, Licciardello V, Barbato E. Soft tissue changes following the extraction of premolars in nongrowing patients with bimaxillary protrusion. Angle Orthod. 2010; 80(1): 211-6. PMID: 19852663.

[2]. Reznikov N, Har-Zion G, Barkana I, Abed Y, Redlich M. Measurement of friction forces between stainless steel wires and "reduced-friction" selfligating brackets. Am J Orthod Dentofacial Orthop. 2010; 138(3): 330-8. PMID: 20816303.

[3]. Krishnan S, Pandian S, Kumar S A. Effect of bisphosphonates on orthodontic tooth movement-an update. J Clin Diagn Res. 2015; 9(4): ZE01-5. PMID: 26023659.

[4]. Tweed CH. A philosophy of orthodontic treatment. Am J Orthod Oral Surg. 1945; 31(2): 74-103.

[5]. Tweed CH. Clinical orthodontics. CV Mosby; 1966.

[6]. Tweed CH. The Application of the Principles of the Edge-wise Arch in the Treatment of Malocclusions: I. Angle Orthod. 1941; 11(1): 5-11.

[7]. Storey E. Force in orthodontics and its relation to tooth movement. Australian J. Dent. 1952; 56: 11-8.

[8]. Begg PR. Differential force in orthodontic treatment. Am J Orthod. 1956; 42(7): 481-510.

[9]. Proffit WR, Fields 3rd HW. Contemporary orthodontics 3rd ed. St. Louis: CV Mosby. 2000:185-95.

[10]. ROTH R. Treatment Mechanics for the Straight Wire Appliance, in Orthodontics. Current Principles and Techniques. 1985.

[11]. Kuhlberg AJ. Steps in orthodontic treatment. Textbook of orthodontics. 2001; 232-45.

[12]. Staggers JA, Germane N. Clinical considerations in the use of retraction mechanics. J Clin Orthod. 1991; 25(6): 364-9. PMID: 1939634.

[13]. Heo W, Nahm D-S, Baek S-H. En masse retraction and two-step retraction of maxillary anterior teeth in adult Class I women. Angle Orthod. 2007; 77(6): 973-8. PMID: 18004930.

[14]. Samantha C, Sundari S, Chandrasekhar S, Sivamurty G, Dinesh S. Comparative Evaluation of Two Bis-GMA Based Orthodontic Bonding Adhesives - A Randomized Clinical Trial. J Clin Diagn Res. 2017; 11(4): ZC40-ZC44. PMID: 28571259

[15]. Kamisetty SK, Verma JK, Arun, Sundari S, Chandrasekhar S, Aravind Kumar. SBS vs Inhouse Recycling Methods-An Invitro Evaluation. J Clin Diagn Res. 2015; 9(9): ZC04-8. PMID: 26501002.

[16]. Viswanath A, Ramamurthy J, Dinesh SPS, Srinivas A. Obstructive sleep apnea: Awakening the hidden truth. Niger J Clin Pract. 2015; 18(1): 1-7. PMID: 25511335.

[17]. Rubika J, Felicita AS, Sivambiga V. Gonial angle as an indicator for the prediction of growth pattern. World J Dent. 2015; 6(3): 161-3.

[18]. Pandian KS, Krishnan S, Kumar SA. Angular photogrammetric analysis of the soft-tissue facial profile of Indian adults. Indian J Dent Res. 2018; 29(2): 137-43. PMID: 29652003.

[19]. Ramesh Kumar KR, Shanta Sundari KK, Venkatesan A, Chandrasekar S. Depth of resin penetration into enamel with 3 types of enamel conditioning methods: a confocal microscopic study. Am J Orthod Dentofacial Orthop. 2011; 140(4): 479-85. PMID: 21967934.

[20]. Felicita AS. Orthodontic management of a dilacerated central incisor and partially impacted canine with unilateral extraction - A case report. Saudi Dent J. 2017; 29(4): 185-93. PMID: 29033530.

[21]. Felicita AS, Chandrasekar S, Shanthasundari KK. Determination of craniofacial relation among the subethnic Indian population: a modified approach - (Sagittal relation). Indian J Dent Res. 2012; 23(3): 305-12. PMID: 23059564.

[22]. Felicita AS. Orthodontic extrusion of Ellis Class VIII fracture of maxillary lateral incisor-The sling shot method. The Saudi dental journal. 2018; 30(3): 265-9. PMID: 29942113.

[23]. Dinesh SPS, Arun AV, Sundari KKS, Samantha C, Ambika K. An indigenously designed apparatus for measuring orthodontic force. J Clin Diagn Res. 2013; 7(11): 2623-6. PMID: 24392423.

[24]. Makhlouf M, Aboul-Ezz A, Fayed MS, Hafez H. Evaluating the Amount of Tooth Movement and Root Resorption during Canine Retraction with Friction versus Frictionless Mechanics Using Cone Beam Computed Tomography. Open Access Maced J Med Sci. 2018; 6(2): 384-8. PMID: 29531610.

[25]. Rhee JN, Chun YS, Row J. A comparison between friction and frictionless mechanics with a new typodont simulation system. Am J Orthod Dentofacial Orthop. 2001; 119(3): 292-9. PMID: 11244423.

[26]. Hayashi K, Uechi J, Murata M, Mizoguchi I. Comparison of maxillary canine retraction with sliding mechanics and a retraction spring: a threedimensional analysis based on a midpalatal orthodontic implant. Eur J Orthod. 2004; 26(6): 585-9. PMID: 15650067.

[27]. Sivamurthy G, Sundari S. Stress distribution patterns at mini-implant site during retraction and intrusion-a three-dimensional finite element study. Prog Orthod. 2016; 17(1): 4. PMID: 26780464.

[28]. Vikram NR, Prabhakar R, Kumar SA, Karthikeyan MK, Saravanan R. Ball Headed Mini Implant. J Clin Diagn Res. 2017; 11(1): ZL02-3. PMID: 28274084.

[29]. Jain RK, Kumar SP, Manjula WS. Comparison of intrusion effects on maxillary incisors among mini implant anchorage, $\mathrm{j}$-hook headgear and utility arch. J Clin Diagn Res. 2014; 8(7): ZC21-4. PMID: 25177631.

[30]. Felicita AS. Quantification of intrusive/retraction force and moment generated during en-masse retraction of maxillary anterior teeth using mini-implants: A conceptual approach. Dental Press J Orthod. 2017; 22(5): 47-55. PMID: 29160344 